\title{
Comparative pharmacokinetics of borneol in cerebral ischemia-reperfusion and sham-operated rats*
}

\author{
Pan XU, Ying LI, Shou-ying DU ${ }^{\dagger \ddagger}$, Yang LU ${ }^{\dagger \ddagger}$, Jie BAI, Qing-li GUO \\ (Department of Industrial Pharmacy, School of Chinese Pharmacy, Beijing University of Chinese Medicine, Beijing 100102, China) \\ †E-mail: dushouying@263.net; landocean28@163.com \\ Received May 15, 2013; Revision accepted Sept. 11, 2013; Crosschecked Dec. 24, 2013
}

\begin{abstract}
Objective: This study was designed to investigate the pharmacokinetics of borneol in the pathological conditions of stroke and evaluate the pharmacokinetic differences of borneol caused by stroke after oral administration of borneol and Xingnaojing (XNJ). Methods: The rats were divided into two groups, ischemia-reperfusion (IR) and sham-operated (SO) rats. Each group contained two subgroups: pure borneol and XNJ subgroups. After administration with the same dosages of borneol $162.0 \mathrm{mg} / \mathrm{kg}$, plasma samples were collected. The cerebral ischemia-reperfusion model was created by reversible middle cerebral artery occlusion (MCAO). The blood samples were collected punctually after oral administration and a specific gas chromatographic system-flame ionization detector (GC-FID) method was developed and employed to determine the level of borneol in the plasma. The pharmacokinetic parameters were analyzed using non-compartmental methods with Kinetica. Results: After administration of borneol, the maximum plasma concentration $\left(C_{\max }\right)$ and area under the curve (AUC) values in stroke rats significantly increased by $302 \%$ and $275 \%$, respectively, compared with the SO rats, and the same phenomenon appeared after administration of XNJ. In the rats with the same physiological conditions, the $C_{\max }$ and $A \cup C$ had higher values in the borneol subgroup $(P<0.05)$. Conclusions: These results suggest that the pathological damages of ischemia-reperfusion have a significant impact on the pharmacokinetic traits of borneol and that there are some components in XNJ inhibiting the absorption of borneol.
\end{abstract}

Key words: Borneol, Pharmacokinetics, Cerebral ischemia-reperfusion, Xingnaojing

doi: 10.1631 jzus.B1300141

Document code: A

CLC number: R91

\section{Introduction}

Stroke is defined as an acute neurologic dysfunction of vascular origin with sudden or rapid occurrence of symptoms and signs corresponding to the involvement of focal areas in the brain (Goldstein et al., 1989). Cerebral ischemia and hemorrhage, its two main types, account for $85 \%$ and $15 \%$, respectively (Meairs et al., 2006). Stroke is a common cause of death and disability in adults worldwide and its inci-

\footnotetext{
${ }^{\sharp}$ Corresponding authors

* Project supported by the Innovation Team Development Program of Beijing University of Chinese Medicine (No. 2011-CXTD-13), the Independent Project of Beijing University of Chinese Medicine (No. 2013-JYBZZ-XS-093), and the Technology Major Projects of China (No. 2014ZX09301306-008)

(C) Zhejiang University and Springer-Verlag Berlin Heidelberg 2014
}

dence is becoming higher with an aging population. Xingnaojing (XNJ) is an effective traditional Chinese medicine (TCM) preparation to treat stroke. It is derived from An Gong Niu Huang Wan and consists of only four herbs, namely, moschus, Gardenia jasminoides Ellis, borneol, and Curcuma aromatica Salisb, maintaining the original potency. Now it has been used in the therapy of strokes as an injection in China and other Asia countries with good results (Cai et al., 2000; Guo et al., 2010). However, because the drawbacks that include inconvenience, expensiveness and several adverse reactions of injection, more researchers (Lu et al., 2011a; 2011b) are focusing on safer methods of administration including the development of an oral solid preparation of XNJ.

Borneol is an effective component in XNJ. Reports showed that borneol shares many bioactivities 
such as anti-inflammatory (Ehrnhöfer-Ressler et al., 2013), antithrombotic (Li et al., 2008), improvement of the energy metabolism (Liu et al., 2011), and protection against cerebral ischemic damage (Imanshahidi and Hosseinzadeh, 2006). Besides, borneol can accelerate the opening of the blood-brain barrier (BBB), improving the penetration and bioavailability of other drugs (Li et al., 2007; Dai et al., 2009). So it has been widely used in clinics. Though the pharmacokinetics of borneol have been reported (Huang et al., 2009; Zhao et al., 2012), as we all know, the patients are the ultimate consumers of drugs according to the "prescription response to the symptom" theory, and the pharmacokinetics under pathological conditions and the influence of stroke on the pharmacokinetics are necessary for research.

In our current study, we utilize the middle cerebral artery occlusion (MCAO) model to investigate the pharmacokinetic characteristics of borneol under pathological conditions after oral administration of XNJ or borneol. A sham-operated (SO) group was also set up for comparison and to evaluate the influence of a stroke on pharmacokinetics. Differences in pharmacokinetics of borneol after oral administration of XNJ decoction or pure borneol between MCAO and $\mathrm{SO}$ rats are illustrated. It will be our intent to indicate the influence of the factors including the state of the stroke and the other components in XNJ on the pharmacokinetics of borneol, and furthermore, to supply more information in the clinical use of borneol and also establish a better foundation to develop the oral solid XNJ preparation.

\section{Materials and methods}

\subsection{Materials and reagents}

Borneol was purchased from the Guizhou Golden Pharmaceutical Co., Ltd., China. XNJ oral tablets were prepared in our laboratory. Borneol reference standards (Fig. 1) were provided from the National Institute for the Control of Pharmaceutical and Biological Products (NICPBP, Beijing, China). Octadecane as an internal standard (Lon et al., 2011) was purchased from the Guangfu Fine Chemical Research Institute (Tianjin, China). The ethyl acetate used was of chromatography grade (Fisher Scientific, USA).

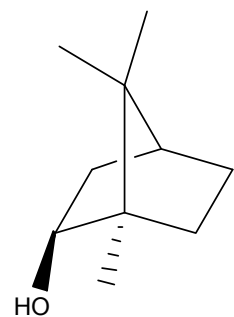

Fig. 1 Chemical structure of borneol

\subsection{Preparation of oral medicine}

Fine borneol powder was weighed and dissolved in $0.7 \%(7 \mathrm{~g} / \mathrm{L})$ carboxymethylcellulose sodium (CMC$\mathrm{Na})$ aqueous solution. XNJ tablets were grinded and also suspended in $0.7 \% \mathrm{CMC}-\mathrm{Na}$ solution, and then mixed them into the concentration containing borneol $16.2 \mathrm{mg} / \mathrm{ml}$ for preparation of the animal oral administration.

\subsection{Instrumentation and chromatographic conditions}

A GC-FID system, comprised of a Techcomp D7980 gas chromatographic (GC) system, a flame ionization detector (FID), and Techcomp Chemstation software for data analysis (Tianmei Scientific Instrument Company, Shanghai, China), was used in this study. The separation of borneol and octadecane was performed with a high performance capillary column (Techcomp TM-1701; $30 \mathrm{~m} \times 0.32 \mathrm{~mm} \times 0.25 \mu \mathrm{m}$ ). Nitrogen, at a flow rate of $30 \mathrm{ml} / \mathrm{min}$, was used as the carrier gas. The oven temperature was programmed to rise from an initial temperature of $105^{\circ} \mathrm{C}$ (remained for $8 \mathrm{~min}$ ) to $185^{\circ} \mathrm{C}$ at a rate of $50{ }^{\circ} \mathrm{C} / \mathrm{min}$ and held isothermally at $185{ }^{\circ} \mathrm{C}$ for $6 \mathrm{~min}$, then to rise to $250{ }^{\circ} \mathrm{C}$ by post run for $6 \mathrm{~min}$. The injection port temperature was $250{ }^{\circ} \mathrm{C}$ and detector temperature was maintained at $300{ }^{\circ} \mathrm{C}$. Then $1 \mu \mathrm{l}$ of samples were injected automatically.

\subsection{Animals}

Male Sprague-Dawley (SD) rats, weighing 240-260 g, were purchased from the Weitong biotechnology Inc. (Beijing, China). All animals were housed under standard conditions of temperature, humidity, and light, and ad libitum fed with water and food before the experiments. The animals were fasted for $12 \mathrm{~h}$ with free access to water prior to administration and the investigation was conducted in accordance with the Regulation for the Administration 
of Affairs Concerning Experimental Animals (State Science and Technology Commission, 1988).

\subsection{Sample preparation}

A total of $20 \mu \mathrm{l}$ octadecane solution (internal standard, $60.0 \mathrm{~g} / \mathrm{ml}$ in ethyl acetate) was added into the $180 \mu \mathrm{l}$ plasma sample. After vortex-mixing for $1 \mathrm{~min}, 200 \mu \mathrm{l}$ of ethyl acetate was added. The mixture was vortex-mixed for $30 \mathrm{~s}$ and centrifuged for $5 \mathrm{~min}$ at $10000 \mathrm{r} / \mathrm{min}$, and then $1 \mu \mathrm{l}$ of supernatant fluid was injected into the GC system for analysis.

\subsection{Assay method validation}

The assay of borneol in rat plasma was developed and validated as follows. The specificity was evaluated by comparing the different samples, and there was no interference to the analyses of main components (Fig. 2).

The $20 \mu \mathrm{l}$ borneol solutions at different concentrations were added into the $180 \mu \mathrm{l}$ blank rat plasmas to prepare a series of standard samples. They showed a good linearity $(r=0.9998)$ at the concentrations of $0.1128,0.5639,1.1280,2.2556,5.6390,11.2800$, and $18.0400 \mu \mathrm{g} / \mathrm{ml}$ and the lower limit of quantification (LLOQ) for borneol was $0.0564 \mu \mathrm{g} / \mathrm{ml}$ while the signal-to-noise ratio $(\mathrm{S} / \mathrm{N})$ is 10 .

Validation was performed with the quality control (QC) samples at three different concentrations of $0.5639,5.6390$, and $18.0400 \mu \mathrm{g} / \mathrm{ml}$. The extraction recovery was $100.48 \%$ to $106.19 \%$. The stability of the sample storage (at room temperature for $4 \mathrm{~h}$, at $-20{ }^{\circ} \mathrm{C}$ for $7 \mathrm{~d}$ ) was assessed with the relative error (RE) less than $\pm 10 \%$ for all samples. The intra-day and inter-day precisions were evaluated by assay QC samples in a single day and three consecutive days. The results are shown in Table 1. All results of the assay validation verified the accuracy and stability of the GC methods.

Table 1 Precision and accuracy of the determination of borneol in rat plasma

\begin{tabular}{cccccc}
\hline \multirow{2}{*}{$\begin{array}{c}c_{\mathrm{B}} \\
(\mu \mathrm{g} / \mathrm{ml})\end{array}$} & \multicolumn{2}{c}{ Intra-day } & & \multicolumn{2}{c}{ Inter-day } \\
\cline { 2 - 3 } \cline { 5 - 6 } \cline { 5 - 6 } & $\mathrm{RSD}(\%)$ & $\mathrm{RE}(\%)$ & & $\mathrm{RSD}(\%)$ & $\mathrm{RE}(\%)$ \\
\hline 0.56 & 0.32 & 9.98 & & 2.51 & -5.88 \\
5.64 & 3.36 & 4.69 & & 3.11 & -8.31 \\
18.04 & 4.42 & -0.86 & & 6.48 & -2.34 \\
\hline
\end{tabular}

$c_{\mathrm{B}}$ : borneol concentration; RSD: relative standard deviation: RE: relative error
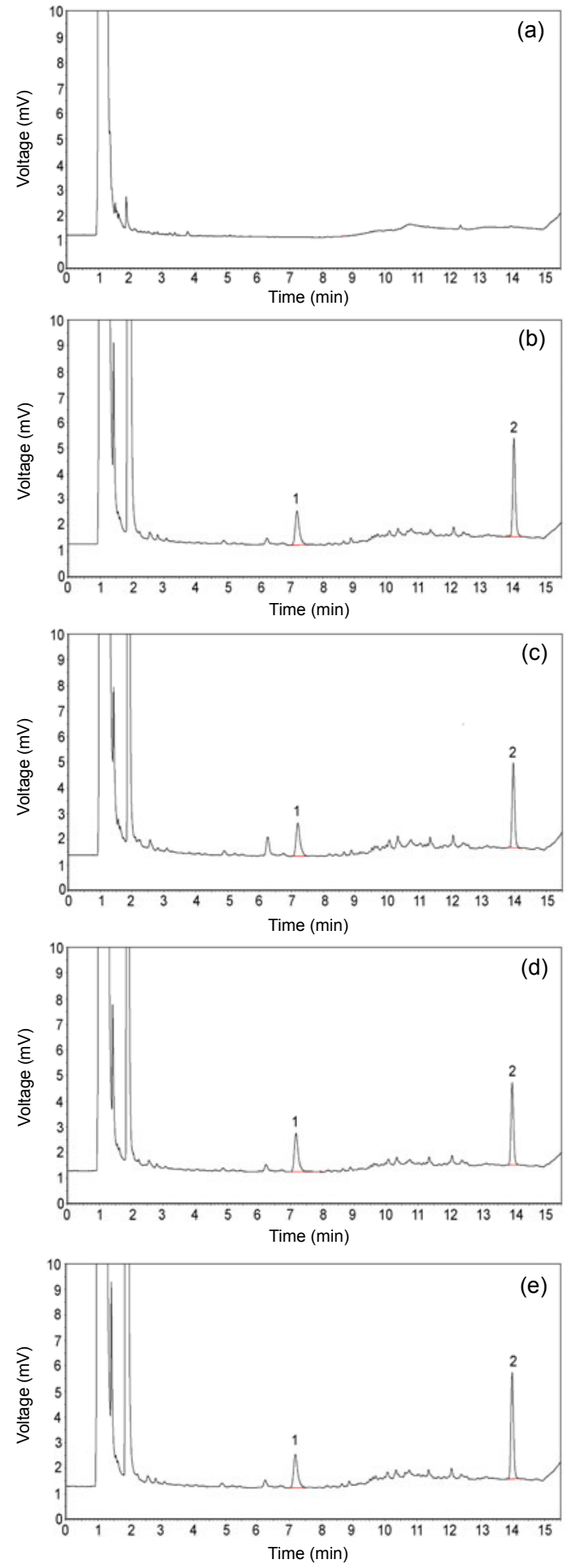

Fig. 2 Chromatograms of borneol in rat plasma (a) A blank plasma; (b) Blank plasma sample spiked with borneol; (c) Blank plasma sample spiked with XNJ; (d) Plasma samples $30 \mathrm{~min}$ after oral administration of $\mathrm{XNJ}$; (e) Plasma samples 30 min after oral administration of borneol (1: borneol; 2: octadecane) 


\subsection{In vivo pharmacokinetic study}

All the rats were divided into two groups: ischemia-reperfusion (IR) and sham-operated (SO) rats. Each group contained two subgroups $(n=5)$ : XNJ and borneol subgroups. The MCAO model rats were induced according to the method of Longa et al. (1989) with minor modifications. Briefly, after isolating the right common carotid artery (CCA), the external carotid artery (ECA), and the internal carotid artery (ICA), we ligated the ECA and CCA, and then a $0.26-\mathrm{mm}$ polylysine-coated nylon monofilament was inserted through the ICA to occlude the middle cerebral artery (MCA) in the brain, followed by a reperfusion $2 \mathrm{~h}$ later. As a control, the SO rats were prepared like the model except that a filament insertion was utilized.

The pharmacokinetic study was performed $24 \mathrm{~h}$ after reperfusion in the model groups, i.e., $26 \mathrm{~h}$ after operation in the SO group. The XNJ subgroup rats were orally administered with XNJ decoction dissolved in $0.7 \%$ CMC-Na aqueous solution $(10.00 \mathrm{ml} / \mathrm{kg}$ body weight $(\mathrm{BW})$ ). The pure borneol subgroup also received gavages of borneol suspension $(10.00 \mathrm{ml} / \mathrm{kg}$ BW). Borneol and XNJ suspensions were administrated respectively at a dosage of $162.0 \mathrm{mg} / \mathrm{kg}$ of borneol. Then $0.5 \mathrm{ml}$ plasma samples were collected into heparinized tubes by the puncture of the retroorbital sinus at 5, 10, 20, 30, 45, 60, 90, 120, 180, 240, and $360 \mathrm{~min}$ separately following oral administration. After centrifugation at $6000 \mathrm{r} / \mathrm{min}$ for $10 \mathrm{~min}$, plasma samples were stored at $-20{ }^{\circ} \mathrm{C}$ and analyzed within one week.

\subsection{Data analysis}

Experimental data and pharmacokinetic parameters are expressed as mean \pm standard deviation (SD). Plasma concentration-time curves were plotted, and the maximum plasma concentration $\left(C_{\max }\right)$ and the corresponding time $\left(T_{\max }\right)$ values were obtained directly from them. The pharmacokinetic parameters such as area under the curve from time zero to last sampling time $\left(\mathrm{AUC}_{0-t}\right)$, terminated half-life $\left(t_{1 / 2}\right)$, and the mean residence time (MRT) were calculated by non-compartmental methods using a Kinetica Version 4.4 (Innaphase, MA, USA). Statistical comparisons among four groups were performed with SPSS Version 17.0 (SPSS Inc., Chicago, IL, USA) using unpaired Student's $t$-test with $P<0.05$ as the level of significance.

\section{Results}

The validated GC method was successfully applied to the pharmacokinetic study of borneol after oral administration of pure borneol or XNJ suspension. The mean plasma concentration-time curve profile of borneol is illustrated in Fig. 3 and shows a single peak phenomenon with rapid absorption and excretion in all groups. Borneol could be detected in the rats' plasma in 5 min after oral administration and $90 \%$ of the borneol is eliminated within $4 \mathrm{~h}$. However, pharmacokinetic differences existed obviously between the IR and SO groups or borneol and XNJ subgroups. The pharmacokinetic parameters are shown in Table 2 in detail after two-way analysis of variance (ANOVA).
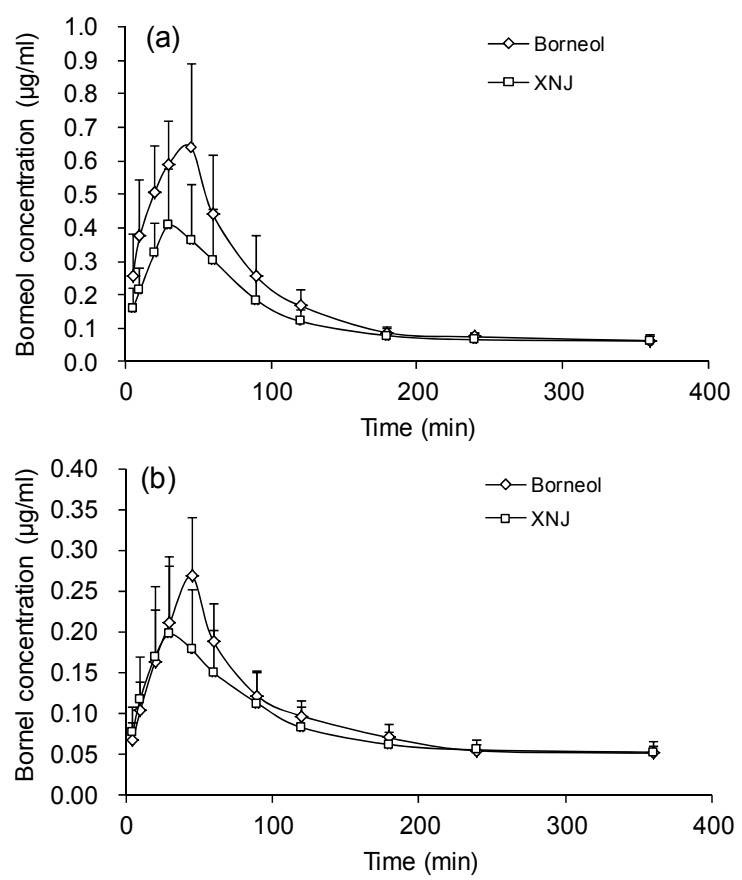

Fig. 3 Plasma concentration-time curves of borneol in IR (a) and SO (b) rats after oral administration of XNJ or pure borneol

Data are expressed as mean $\pm \mathrm{SD}(n=5)$ 


\subsection{Borneol in rats of different pharmacological states (ischemia-reperfusion or sham-operated)}

As shown in Table 2, after administration of borneol, there were statistically significant differences in the parameters including the $C_{\max }, \mathrm{AUC}_{0-t}$, and $\mathrm{AUC}_{0-\infty}$ between the IR and SO rats. Particularly, the borneol of plasma in the IR rats attained $C_{\max }[(5.41 \pm 1.43) \mu \mathrm{g} / \mathrm{ml}]$ at $39 \mathrm{~min}$, while $\mathrm{AUC}_{0-t}$ and $\mathrm{AUC}_{0-\infty}$ were $(428.18 \pm$ $109.05)$ and $(460.57 \pm 114.68)(\mu \mathrm{g} / \mathrm{ml}) \cdot \mathrm{min}$. On the contrary, the values of $C_{\max }, \mathrm{AUC}_{0-t}$, and $\mathrm{AUC}_{0-\infty}$ in the SO group decreased significantly $(P<0.05)$ with a longer $T_{\max }[(42 \pm 6.71) \mathrm{min}]$. MRT and $t_{1 / 2}$ in the IR rats were also increased compared to the SO rats, but the growth is not significant because of the greater variability and small numbers of animals. Similar to the rats given borneol, the $C_{\max }, \mathrm{AUC}_{0-t}$, and $\mathrm{AUC}_{0-\infty}$ were bigger in the IR rats when administrated with $\mathrm{XNJ}$ suspension. The above findings suggest that cerebral ischemia-reperfusion improves the absorption of borneol and influences its pharmacokinetics trait.

\subsection{Borneol in rats administrated with different suspensions (borneol or $\mathrm{XNJ}$ )}

Whether in IR or SO rats, $C_{\max }, \mathrm{AUC}_{0-t}$, and $\mathrm{AUC}_{0-\infty}$ were much larger after administrated with borneol compared to $\mathrm{XNJ}(P<0.05)$, though borneol in rats given $\mathrm{XNJ}$ reached $C_{\max }$ with lower $T_{\max }$ and $C_{\max }$ became lesser too. As Fig. 3 shows, those differences were more obvious in the IR group. The above results showed that borneol was absorbed better when rats were given it alone.

\section{Discussion}

With the progress of pharmacokinetic research, more importance has been paid to the influence of pathological status on drug procession. Many researchers have demonstrated that hepatic disease leads to a higher plasma concentration and lower clearance rate in the metabolism of drugs (Pieniaszek et al., 1994; Rodighiero, 1999). Considering that stroke is becoming a worldwide mental disease (Kaste $e t$ al., 1998; Meairs et al., 2006), it is necessary to research its effects on drugs. In this study, we chose the MCAO model to imitate the abnormal state of stroke. This transient focal ischemic model is distinguished by its severe contralateral hemiparesis and ipsilateral Horner's syndrome, which is close to the status of strokes in humans. It is widely used in scientific research (Truong et al., 2012). Many researchers had indicated that the permeability of BBB after reperfusion subsequent to cerebral ischemia increases gradually in $24 \mathrm{~h}$ to the peak, and begins to decrease at the $48 \mathrm{~h}$ time point (Rosenberg et al., 1998; Wu et al., 2006). So the administration time was chosen at the $24 \mathrm{~h}$ time point after reperfusion. In order to diminish the influence of the operation on the rat's pharmacological status, an SO group was included. The comparison of pharmacokinetic traits between IR and SO rats showed the influence of cerebral ischemiareperfusion on drugs successfully.

Because of its pharmacological activity, absorption enhancement (Li et al., 2006), and its ability of helping other drugs to penetrate through BBB (Cai et al., 2008), borneol has been widely used in TCM

Table 2 Pharmacokinetic parameters of borneol in rats after oral administration of pure borneol or XNJ $(162.0 \mathrm{mg} / \mathrm{kg}$ of borneol)

\begin{tabular}{lcccccc}
\hline \multicolumn{1}{c}{ Group } & $\begin{array}{c}C_{\max } \\
(\mu \mathrm{g} / \mathrm{ml})\end{array}$ & $\begin{array}{c}T_{\max } \\
(\mathrm{min})\end{array}$ & $\begin{array}{c}\mathrm{AUC}_{0-t} \\
{[(\mu \mathrm{g} / \mathrm{ml}) \cdot \mathrm{min}]}\end{array}$ & $\begin{array}{c}\mathrm{AUC}_{0-\infty} \\
{[(\mu \mathrm{g} / \mathrm{ml}) \cdot \mathrm{min}]}\end{array}$ & $\begin{array}{c}t_{1 / 2} \\
(\mathrm{~min})\end{array}$ & $\begin{array}{c}\text { MRT } \\
(\mathrm{min})\end{array}$ \\
\hline IR & & & & & & \\
$\quad$ Pure borneol & $5.41 \pm 1.43^{* \#}$ & $39 \pm 8.21$ & $428.18 \pm 109.05^{* \#}$ & $460.57 \pm 114.68^{* \#}$ & $107.99 \pm 38.45$ & $117.09 \pm 25.87$ \\
$\quad$ XNJ & $2.88 \pm 1.21$ & $32 \pm 9.08$ & $263.81 \pm 88.43$ & $304.05 \pm 95.40$ & $127.68 \pm 85.64$ & $165.61 \pm 90.81$ \\
SO & & & & & & \\
$\quad \begin{array}{l}\text { Pure borneol } \\
\text { XNJ }\end{array}$ & $1.79 \pm 0.49^{*}$ & $42 \pm 6.71$ & $155.42 \pm 41.89^{*}$ & $171.57 \pm 42.83^{*}$ & $84.97 \pm 20.92$ & $144.72 \pm 40.80$ \\
& $1.23 \pm 0.67$ & $36 \pm 8.21$ & $131.55 \pm 60.61$ & $149.12 \pm 74.18$ & $106.36 \pm 24.45$ & $151.05 \pm 53.09$ \\
\hline
\end{tabular}

Data are expressed as mean $\pm \mathrm{SD}(n=5) .{ }^{*} P<0.05$, versus oral administration of XNJ in the same group; ${ }^{*} P<0.05$, versus oral administration of pure borneol in SO group 
prescription treating strokes including XNJ (Zeng et al., 2013). It is necessary to research the pharmacokinetics of borneol entirely. Considering that borneol or the other components of high plasma concentrations will lead to adverse reaction, even toxicity (Hou et al., 2008; Liu et al., 2010; Li et al., 2011), we increased the prescription dosage to $162.0 \mathrm{mg} / \mathrm{kg}$ of borneol based on previous studies (Huang et al., 2006; Xiao et al., 2007). Due to the severe symptoms and many complications after strokes, the patients' physiological status changes a lot. The pharmacokinetic study in the state of stroke is meaningful and this study is the first attempt to investigate the effect of cerebral ischemia-reperfusion on pharmacokinetics of borneol. The results demonstrated significantly higher $C_{\max }, \mathrm{AUC}_{0-t}$, and $\mathrm{AUC}_{0-\infty}$ in the IR rats compared to the $\mathrm{SO}$ rats. As a small liposoluble monoterpenoid molecular, borneol could pass through the gastric mucosa easily at all time. The better absorption in stroke rats may result from the following reasons: (1) Firstly, stroke would cause the hemorrhage of the upper gastrointestinal tract, which occurs with the syndromes of over-abundance gastric acid, gastric mucosa festering, and ulcer (Otegbayo et al., 2006). It means that the gastric mucosa barrier is open to borneol, and therefore, more borneol will be absorbed (2) Secondly, fever following reperfusion was observed in this study, it accords with research on humans with strokes (Georgilis et al., 1999). The abnormal temperature will increase the blood flow, which brings more plasma protein to combine with borneol in a certain time period. What is more, poor ability to remove drugs off at per time unit in the state of pathophysiology may contribute to a larger AUC. In conclusion, the effects of ischemic stroke on the absorption, distribution, and metabolism of borneol will lead to a different pharmacokinetics of borneol.

Considering that XNJ consists of four herbs and other components may also influence the pharmacokinetics of borneol, we gave the rats XNJ orally and found that the pharmacokinetic differences between IR rats and SO rats still existed. A larger $C_{\max }$ and $\mathrm{AUC}_{0-t}$ were observed in the IR group though other components may influence borneol. When focusing on rats of the same physiological state, the pharmacokinetic differences of borneol were significant between the borneol and the XNJ subgroups.
The values of $C_{\max }, T_{\max }$, and AUC decreased when rats were given XNJ. It indicated that other herbal components can indeed influence the pharmacokinetics of borneol. The major components except borneol contained in $\mathrm{XNJ}$ are geniposide, muscone and Curcuma aromatica volatile oil. Research has indicated that those three components all have antiinflammatory activity (Li, 1985; Wang et al., 2000; Koo et al., 2006), so they may relieve fever effectively by acting on the infection following stroke. Lee et al. (2009) also reported that geniposide shows acid-neutralizing capacities and also antioxidant activities. Therefore, geniposide can protect the gastric mucosa after stroke occurred and influence the permeation of borneol subsequently. What is more, drug interactions in XNJ may lead to a pharmacokinetic change after administration of the prescription. Though the exact mechanism is ambiguous, the pharmacokinetic differences of borneol in rats given different drug forms should be given attention to.

\section{Conclusions}

In summary, this study demonstrated in an animal model that the ischemic stroke alters the pharmacokinetics of borneol in such a way that at a given dosage of borneol (or XNJ), the IR rats have bigger $C_{\max }$ and AUC. These results illustrate the rationality of using borneol in stroke treatment. The pharmacokinetic differences of borneol between rats given borneol and rats given $\mathrm{XNJ}$ were also observed and other components will influence the pharmacokinetics of borneol and make a foundation for the development of oral preparation of XNJ. Considering that borneol was often used with other drugs in clinics to treat stroke, our above investigation about the pharmacokinetics of borneol will help to guide the clinical application of borneol and prescriptions containing borneol in patients with strokes.

\section{Compliance with ethics guidelines}

Pan XU, Ying Li, Shou-ying DU, Yang LU, Jie BAI, and Qing-li GUO declare that they have no conflict of interest.

All institutional and national guidelines for the care and use of laboratory animals were followed. 


\section{References}

Cai, D.F., Zhao, J.H., Ruan, Q.M., et al., 2000. Clinical and experimental study on Xingnaojing injection in treating acute ischemic cerebral apoplexy. J. Emerg. Tradit. Chin. Med., 9(2):45-47 (in Chinese). [doi:10.3969/j.issn.1004745X.2000.02.001]

Cai, Z., Hou, S., Li, Y., et al., 2008. Effect of borneol on the distribution of gastrodin to the brain in mice via oral administration. J. Drug Target., 16(2):178-184. [doi:10. 1080/10611860701794395]

Dai, J.P., Chen, J., Bei, Y.F., et al., 2009. Influence of borneol on primary mice oral fibroblasts: a penetration enhancer may be used in oral submucous fibrosis. J. Oral Pathol. Med., 38(3):276-281. [doi:10.1111/j.1600-0714.2008. 00738.x]

Ehrnhöfer-Ressler, M.M., Fricke, K., Pignitter, M., et al., 2013. Identification of 1,8-cineole, borneol, camphor, and thujone as anti-inflammatory compounds in a Salvia officinalis L. infusion using human gingival fibroblasts. $J$. Agric. Food Chem., 61(14):3451-3459. [doi:10.1021/ jf305472t]

Georgilis, K., Plomaritoglou, A., Dafni, U., et al., 1999. Aetiology of fever in patients with acute stroke. J. Intern. Med., 246(2):203-209. [doi:10.1046/j.1365-2796.1999. 00539.x]

Goldstein, M., Barnett, H.J.M., Orgogozo, J.M., et al., 1989. Stroke-1989: recommendations on stroke prevention, diagnosis, and therapy. Report of the WHO Task Force on Stroke and Other Cerebrovascular Disorders. Stroke, 20(10):1407-1431. [doi:10.1161/01.STR.20.10.1407]

Guo, F., Lu, X.W., Xu, Q.P., 2010. Protective effect of Xingnaojing and Xuesaitong injections on cerebral ischemic reperfusion injury in rats. Natl. Med. J. China, 90(23): 1645-1648 (in Chinese). [doi:10.3760/cma.j.issn.03762491.2010.23.018]

Hou, Y.C., Tsai, S.Y., Lai, P.Y., et al., 2008. Metabolism and pharmacokinetics of genipin and geniposide in rats. Food Chem. Toxicol., 46(8):2764-2769. [doi:10.1016/j.fct.2008. 04.033]

Huang, P., Jiang, X.F., Zou, J.L., et al., 2009. A novel GC-MS bioanalytical method for natural borneol and its application in investigating natural borneol distribution in mice. World Sci. Technol., 11(6):821-827. [doi:10.1016/S18763553(10)60038-5]

Huang, T.L., Ye, S.M., Ou, W.P., et al., 2006. Comparative study of the pharmacokinetics of borneolum syntheticum and borneol in herbal preparations. Tradit. Chin. Drug Res. Clin. Pharmacol., 17(4):265-267 (in Chinese). [doi: 10.3321/j.issn:1003-9783.2006.04.011]

Imanshahidi, M., Hosseinzadeh, H., 2006. The pharmacological effects of Salvia species on the central nervous system. Phytother. Res., 20(6):427-437. [doi:10.1002/ptr. 1898]

Kaste, M., Fogelholm, R., Rissanen, A., 1998. Economic burden of stroke and the evaluation of new therapies. Public Health, 112(2):103-112. [doi:10.1038/sj.ph.
1900422]

Koo, H.J., Lim, K.H., Jung, H.J., et al., 2006. Antiinflammatory evaluation of gardenia extract, geniposide and genipin. J. Ethnopharm., 103(3):496-500. [doi:10. 1016/j.jep.2005.08.011]

Lee, J.H., Lee, D.U., Jeong, C.S., 2009. Gardenia jasminoides Ellis ethanol extract and its constituents reduce the risks of gastritis and reverse gastric lesions in rats. Food Chem. Toxicol., 47(6):1127-1131. [doi:10.1016/j.fct.2009.01.037]

Li, C.Z., 1985. Anti-inflammatory effect of the volatile oil from Curcuma aromatica. China J. Chin. Mat. Med., 10(3):38-40 (in Chinese).

Li, F., Feng, J., Cheng, Q., et al., 2007. Delivery of ${ }^{125}$ I-cobrotoxin after intranasal administration to the brain: a microdialysis study in freely moving rats. Int. J. Pharm., 328(2):161-167. [doi:10.1016/j.ijpharm.2006.08.011]

Li, L., Yuan, Y., Jiang, X.H., 2006. Absorption mechanism of liposoluble components of Salvia miltiorrhiza with Caco-2 cell model. Chin. Pharm. J., 41(2):108-110 (in Chinese). [doi:10.3321/j.issn:1001-2494.2006.02.009]

Li, W.R., Liu, R., Huang, T.L., et al., 2011. Chronotoxicology study of acute toxicity on natural borneol in mice. Lishizhen Med. Mat. Med. Res., 22(8):1805-1806 (in Chinese). [doi:10.3969/j.issn.1008-0805.2011.08.001]

Li, Y.H., Sun, X.P., Zhang, Y.Q., et al., 2008. The antithrombotic effect of borneol related to its anticoagulant property. Am. J. Chin. Med., 36(4):719-727. [doi:10. 1142/S0192415X08006181]

Liu, R., Zhang, L., Lan, X., et al., 2011. Protection by borneol on cortical neurons against oxygen-glucose deprivation/ reperfusion: involvement of anti-oxidation and antiinflammation through nuclear transcription factor $\mathrm{\kappa B}$ signaling pathway. Neuroscience, 176(10):408-419. [doi: 10.1016/j.neuroscience.2010.11.029]

Liu, Y.H., Shao, F., Wang, Y., et al., 2010. The damage of borneol and its preparation on gastric mucosa in rats. Qilu Pharm. Affairs, 29(14):232-234 (in Chinese). [doi:10. 3969/j.issn.1672-7738.2010.04.018]

Lon, H.K., Liu, D., Zhang, Q., et al., 2011. Pharmacokineticpharmacodynamic disease progression model for effect of etanercept in Lewis rats with collagen-induced arthritis. Pharm. Res., 28(7):1622-1630. [doi:10.1007/s11095011-0396-7]

Longa, E.Z., Weinstein, P.R., Carlson, S., et al., 1989. Reversible middle cerebral artery occlusion without craniectomy in rats. Stroke, 20(1):84-91. [doi:10.1161/01. STR.20.1.84]

Lu, Y., Du, S., Bai, J., et al., 2011a. Bioavailability and brain-targeting of geniposide in gardenia-borneol cocompound by different administration routes in mice. Int J. Mol. Sci., 13(11):14127-14135. [doi:10.3390/ijms 131114127]

Lu, Y., Du, S.Y., Chen, X.L., et al., 2011b. Enhancing effect of natural borneol on the absorption of geniposide in rat via intranasal administration. J. Zhejiang Univ.-Sci. B (Biomed. \& Biotechnol.), 12(2):143-148. [doi:10.1631/jzus. 
B1000121]

Meairs, S., Wahlgren, N., Dirnagl, U., et al., 2006. Stroke research priorities for the next decade: a representative view of the European scientific community. Cerebrovasc. Dis., 22(2-3):75-82. [doi:10.1159/000093098]

Otegbayo, J.A., Talabi, O.A., Akere, A., et al., 2006. Gastrointestinal complications in stroke survivors. Trop Gastroenterol., 27:127-130.

Pieniaszek, H.J., Davidson, A.F., Mcentegart, C.M., et al., 1994. The effect of hepatic disease on the disposition of moricizine in humans. Biopharm. Drug Dispos., 15(3): 243-252. [doi:10.1002/bdd.2510150306]

Rodighiero, V., 1999. Effects of liver disease on pharmacokinetics. Clin. Pharm., 37(5):399-431. [doi:10.2165/ 00003088-199937050-00004]

Rosenberg, G.A., Estrada, E.Y., Dencoff, J.E., 1998. Matrix metalloproteinases and TIMPs are associated with blood-brain barrier opening after reperfusion in rat brain. Stroke, 29(10):2189-2195. [doi:10.1161/01.STR.29.10. 2189]

State Science and Technology Commission, 1988. Regulation for the Administration of Affairs Concerning Experimental Animals. Order No. 2 (in Chinese).

Truong, D.T., Venna, V.R., McCullough, L.D., et al., 2012. Deficits in auditory, cognitive, and motor processing following reversible middle cerebral artery occlusion in mice. Exp. Neurol., 238(2):114-121. [doi:10.1016/j. expneurol.2012.08.011]

Wang, W.J., Zhou, L.E., Bai, J.Y., et al., 2000. Effects of musk glucoprotein on PAF production and cytosolic $\mathrm{Ca}^{2+}$ level in rat polymorphonuclear leukocytes in vitro. China J. Chin. Mat. Med., 25(12):29-32 (in Chinese). [doi:10. 3321/j.issn:1001-5302.2000.12.011]

Wu, S.D., Wan, Q., Xia, F., et al., 2006. Dynamic changes of blood-brain barrier permeability and S100B protein level in serum after acute cerebral ischemia/reperfusion in rats. J. Fourth Mil. Med. Univ., 27(10):902-904 (in Chinese). [doi:10.3321/j.issn:1000-2790.2006.10.011]

Xiao, Y.Y., Ping, Q.N., Chen, Z.P., 2007. The enhancing effect of synthetical borneol on the absorption of tetramethylpyrazine phosphate in mouse. Int. J. Pharm., 337(1-2):74-79. [doi:10.1016/j.ijpharm.2006.12.034]

Zeng, M., Pan, L., Qi, S., et al., 2013. Systematic review of recent advances in pharmacokinetics of four classical Chinese medicines used for the treatment of cerebrovascular disease. Fitoterapia, 88:50-75. [doi:10.1016/j.fitote. 2013.04.006]

Zhao, J.Y., Lu, Y., Du, S.Y., et al., 2012. Comparative pharmacokinetic studies of borneol in mouse plasma and brain by different administrations. J. Zhejiang Univ.-Sci. B (Biomed. \& Biotechnol.), 13(12):990-996. [doi:10.1631/ jzus.B1200142]

\section{中文㩯要：}

\section{本文题目：冰片在中风及假手术大鼠体内的药代动力学研究}

Comparative pharmacokinetics of borneol in cerebral ischemia-reperfusion and shamoperated rats

研究目的：中风的发生对冰片药代动力学特征的影响。

创新要点: 首次对冰片及其中药制剂在脑取血再灌注 (中风病理状态下) 的药代动力学进行研究, 为药 物在中风治疗中的应用提供参考。

研究方法: 采用大脑中动脉堵塞法建立脑缺血中风模型, 中风组和假手术组分别灌胃冰片与醒脑静口服 制剂, 不同时间点眼眀取血后用气相色谱氢火焰离子化检测器（GC-FID）测定, 并用非房 室模型分析药时曲线 (见图 3), 得各药代动力学参数 (见表 2)。

重要结论: 脑取血再灌注损伤 (中风状态) 可以促进冰片的吸收及生物利用, 醒脑静中其他成分对其药 代动力学特征也有一定影响。

关键词组: 冰片; 药代动力学; 脑缺血再灌注; 醒脑静 